\title{
An Internet of Things: The Next Expansion of Mobile Education
}

\author{
Zairina Ibrahim, Md Gapar Md Johar, Che Ku Nurul Hasmaria Che Ku Yahaya, Normy Rafid \\ Abdul Rahman
}

\begin{abstract}
This paper aims to mobile education. This is focus on using a mobile application during session of lesson. Therefore, they need to understand the flow of application with schedule class by a week on times. The class will be on the online distance learning for the students and instructors to conducted. The Internet of Things (IoT) is a new design in the world for the internet devices to connected life in new environment of networking. In fact, there are need to develop a smart network for the new technology in world to enhance the knowledge of digital technology. However, the paper was improved the application used in the mobile education for students and instructors in University. Thus, current research on software development on mobile application for educator is limited to readiness and awareness. This research extends the need for empirical findings from system analyst and top management of software development to enhance the education concept of digital contents to the online distance learning for enriching future technology in mobile education.
\end{abstract}

Index Terms: Internet of Things, Mobile, Education, Digital Contents.

\section{INTRODUCTION}

Nowadays, technology is everything and everywhere. In next expansion of world is included of internet of things and sometimes referred to as the internet of objects. Since a few back of years, this evolution most popular and peoples knowledgeable of that. This research is for an internet of things and focus with mobile education in university. Therefore, it is considering an impact for internet of things an already has on education, communication, business, science, government, and humanity. Precisely, the internet of things in one of the most important and powerful creation in all of human history.

Furthermore, internet of things (IoT) represents the next expansion of people especially for primary school. This concept can help the student to not to brought the heavy bag to the school. In fact, this is can give the impact of health as well.

Revised Manuscript Received on September 22, 2019.

Zairina Ibrahim, Information Technology and Innovation Centre, Management and Science University, University Drive Seksyen 13, Shah Alam 40100, Malaysia.

Md Gapar Md Johar, Information Technology and Innovation Centre, Management and Science University, University Drive Seksyen 13, Shah Alam 40100, Malaysia.

Che Ku Nurul Hasmaria Che Ku Yahaya, Information Technology and Innovation Centre, Management and Science University, University Drive Seksyen 13, Shah Alam 40100, Malaysia.

Normy Rafida Abdul Rahman, Faculty Business Management and Professional Studies, Management and Science University, University Drive Seksyen 13, Shah Alam 40100, Malaysia.
According to Benisch et al. (2011) by researching, an approximately 6.3 billion people living on planet and 500 million devices connected to the internet. In fact, by splitting the number of connected devices by world population, it is less than one (0.08) device for every person. The preview research by Berzowska (2005) definition, IoT didn't yet exist in 2003 because the number of connected things was comparatively small given that ubiquitous devices such as smartphones were just being introduced. Thus, for example, Steve Jobs, Apple's CEO, did not disclose the iPhone until January 9, 2007 at the Macworld conference.

According to Brush et al. (2011), exciting growth of smartphones and tablet PCs brought the number of devices connected to the Internet to 12.5 billion in 2010 , while the world's human population increased to 6.8 billion, making the number of connected devices per person more than 1 (1.84 to be exact) for the first time in history.

\section{LITERATURE REVIEW}

All connected by computing systems, software and services with sensors

embedded in the environment. It will be possible to give an impacting human interaction with globe as completely as the Internet has revolutionised communication as shown in Figure 1.

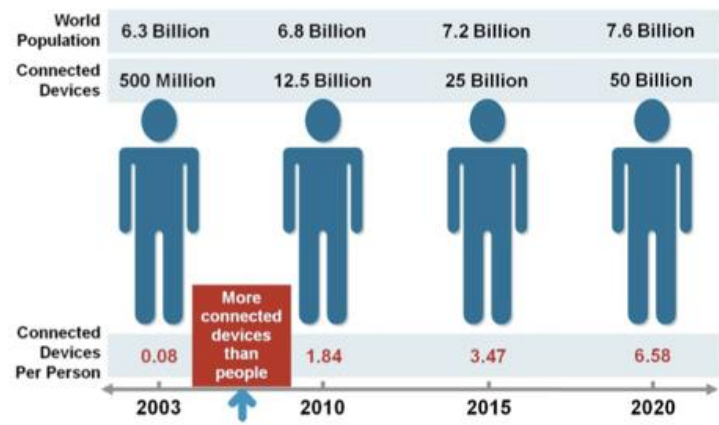

Source: Cisco IBSG April 2011

Fig. 1. The Internet of Things was born between 2008 and 2009.

\section{A. IoT for Network of Network}

Presently, dissimilar of a loose collection in IoT for made up of purpose-built networks. Todays smartphones and Tablets, for example, have multiple networks to control function, safety features, communication systems and software. Nevertheless, commercial and residential buildings as well have various 


\section{An Internet of Things: The Next Expansion of Mobile Education}

control systems for heating, venting, and air conditioning (HVAC), telephone service, security and lighting.

In the late 1980s and early 1990s, for example, Cisco itself by bringing distinct networks together with multi-protocol routing, eventually leading Internet Protocol (IP) as the common networking standard. Escorted by IoT, history is reappeared itself, in progress on a much more scale.

According to Carretero et. al. (2013), the Internet has been on a steady path of development and improvement, but possibly hasn't changed much. It essentially does the same thing that it was designed to do during the ARPANET era. For example, in the early days, there were several communication protocols, including AppleTalk, Token Ring, and IP. Today, the Internet is mainly standardised on IP.

In this context, IoT becomes extremely important because it is the first real evolution of the Internet to a leap that will lead to rotatory applications that have the potential to dramatically improve the way people live, learn, work, and entertain themselves. The IoT has made the Internet sensory (temperature, pressure, vibration, light, moisture, stress), allowing us to become more proactive and less reactive.

In addition, the Internet is develop into places that until now have been unreachable. Patients are ingesting Internet devices into their own bodies to help doctors diagnose and determine the causes of certain diseases.10 Extremely small sensors can be placed on plants, animals, and geologic features, and connected to the Internet.11 At the other end of the spectrum, the Internet is going into space through Cisco's Internet Routing in Space shown as Figure 2 (IRIS) program.12 (Davidoff et al., 2010).

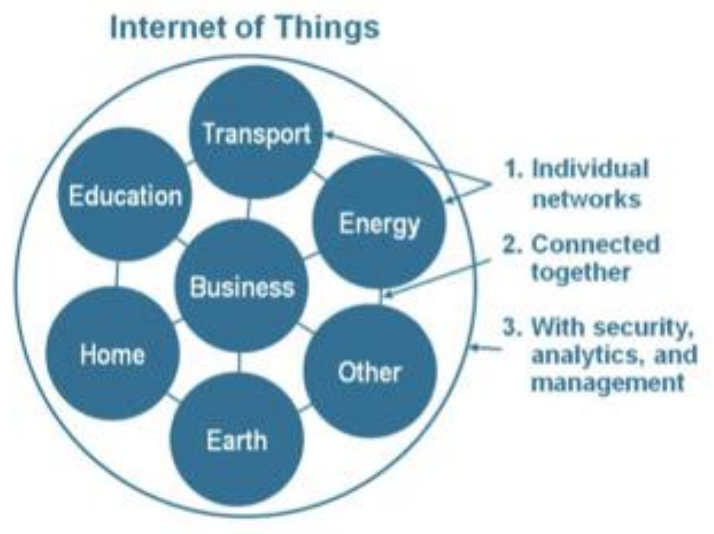

Source: Cisco IBSG April 2011

Fig. 2. IoT Can Be Viewed as a Network of Networks.

\section{B. Important of IoT}

Firstly, necessary is to understand the differences between the Internet and the World Wide Web (WWW) or Web. In Networking conceptual, there have a physical layer in Internet or rework made up of switches, routers and other related equipment. However, its primary function is to transport information from one point to another rapidly, reliably and securely. The web, is an application layer that operates on top of the Internet. Its primary role is to provide an interface that makes the information flowing across the Internet usable.

\section{Expansion of The Web Versus The Internet}

The web has gone through several discordant expansionary stages:

First Stage was the research phase, when the web was called the Advanced Research Projects Agency Network (ARPANET). During this time, the web was primarily used by academia for research purposes. Second Stage is phase of the web can be coined "brochure ware." Characterized by the domain name "gold rush," this stage focused on the need for almost every company to share information on the Internet so that people could learn about products and services. Third Stage is an expansion moved the web from static data to transactional information, where products and services could be bought and sold, and services could be delivered. During this phase, companies like eBay and Amazon.com exploded on the scene. This phase also will be infamously remembered as the "dot-com" boom and bust. Fourth Stage is the "social" or "experience" web, where companies like Facebook, Twitter, and Groupon have become immensely popular and profitable (a notable distinction from the third stage of the web) by allowing people to communicate, connect, and share information (text, photos, and video) about themselves with friends, family, and colleagues.

\section{Expansionary and Communicate}

A human's evacuation because they are communicating. This principle of sharing information and building on discoveries can best be understood by examining how humans process data (see Figure 3). According to Cafaro (2013), from bottom to top, the pyramid layers include data, information, knowledge, and wisdom. Data is the raw material that is processed into information. Individual data by itself is not very useful, but volumes of it can identify trends and patterns. This and other sources of information come together to form knowledge. In the simplest sense, knowledge is information of which someone is aware. Wisdom is then born from knowledge plus experience. While knowledge changes over time, wisdom is timeless, and it all begins with the acquisition of data shown as Figure 3 .

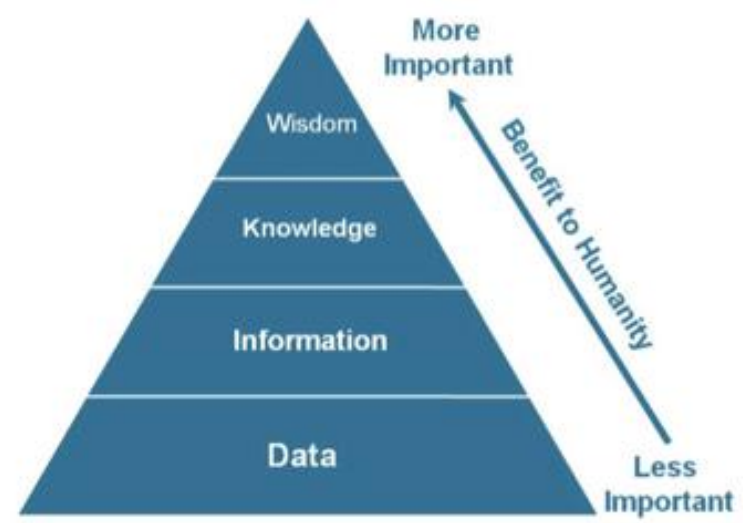

Source: Cisco IBSG April 2011

Fig. 3. Human Turn Data into Wisdom.

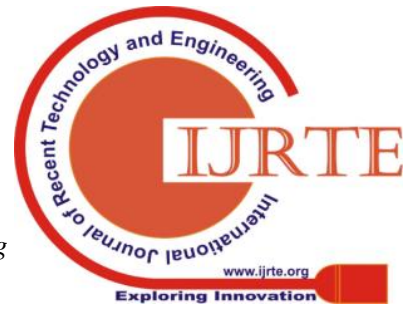


It is also important to note there is a direct correlation between the input (data) and output (wisdom). The more data that is created, the more knowledge and wisdom people can obtain. IoT dramatically increases the amount of data available for us to process. This, coupled with the Internet's ability to communicate this data, will enable people to advance even further.

\section{Critical for Human Progression}

As the planet's population continues to increase, it becomes even more important for people to become stewards of the earth and its resources. In addition, according to Hynes et. al. (2013), people desire to live healthy, fulfilling, and comfortable lives for themselves, their families, and those they care about. By combining the ability of the next evolution of the Internet (IoT) to sense, collect, transmit, analyse, and distribute data on a massive scale with the way people process information, humanity will have the knowledge and wisdom it needs not only to survive, but to thrive in the coming months, years, decades, and centuries.

\section{Improving Quality of Life for the Elderly}

According to Erickson et. al. (2013), the world's population is agings. In fact, approximately 1 billion people age 65 and older will be classified as having reached "non-working age" by the middle of the century.17 IoT can significantly improve quality of life for the surging number of elderly people. For example, imagine a small, wearable device that can detect a person's vital signs and send an alert to a healthcare professional when a certain threshold has been reached, or sense when a person has fallen down and can't get up.

\section{Challenges and Barriers to IoT}

Several barriers, however, have the potential to slow the development of IoT. The three largest are the deployment of IPv6, power for sensors, and agreement on standards (Hong et. al., 2013).

\section{Deployment of IPv6}

The world ran out of IPv4 addresses in February 2010. While no real impact has been seen by the general public, this situation has the potential to slow IoT's progress since the potentially billions of new sensors will require unique IP addresses. In addition, IPv6 makes the management of networks easier due to auto configuration capabilities and offers improved security features (Gaver et. al., 2013).

\section{Sensor energy}

For IoT to reach its full potential, sensors will need to be self-sustaining. Imagine changing batteries in billions of devices deployed across the planet and even into space. Obviously, this isn't possible. What's needed is a way for sensors to generate electricity from environmental elements such as vibrations, light, and airflow.18 In a significant breakthrough, scientists announced a commercially viable nano generator a flexible chip that uses body movements such as the pinch of a finger to generate electricity at the 241st National Meeting \& Exposition of the American Chemical Society in March 19, 2011 (Harrison et. al., 2010).

\section{Standards}

While much progress has been made in the area of standards, more is needed, especially in the areas of security, privacy, architecture, and communications. IEEE is just one of the organisations working to solve these challenges by ensuring that IPv6 packets can be routed across different network types.

It is important to note that while barriers and challenges exist, they are not insurmountable. Given the benefits of IoT, these issues will get worked out. It is only a matter of time (Kamieth et. al., 2013).

\section{METHODOLOGY}

A method that more effectively apply to the research in design automation. Therefore, investigating research already done in design automation reveals that a commonly referred to method is action research. In fact, this method is a subset of research through design that is included in a more general set of methods that capture all aspects of design research.

According to Frayling (1993), originally introduced the method of research through design in the field of design and arts. However, contribution to the development of an accepted view of research by practice or design by describing research through design as an inherent aspect of designer synthesis activities.

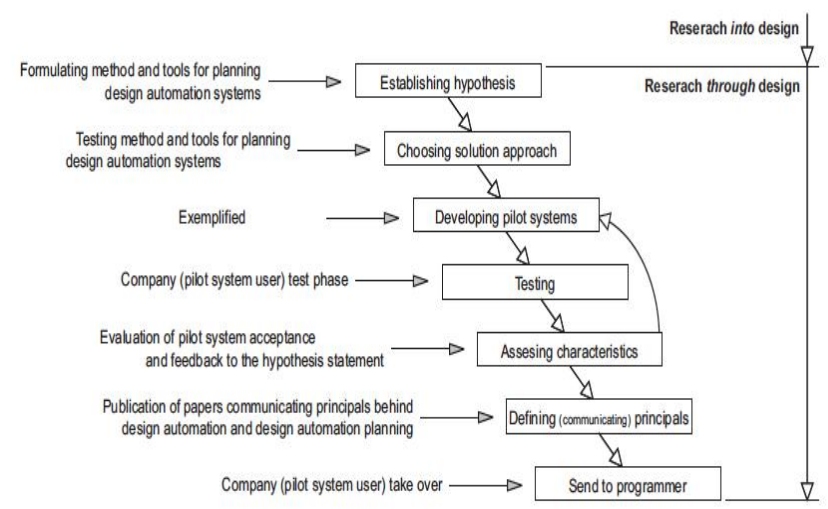

Source: Mikael Cederfeldt, Planning Design Automation: A Structured Method and Supporting Tools, 2007.

Fig. 1. A version of Frayling model of research through art and design as applied to the design of a design automation system (adapted from Home and Ferguson (2003))

According to Mekael Cederfeldt (2007), methodology is applied throughout the performed research work by adopting the aspects of using the project as the laboratory. Thus, research through design, as applied in IoT for mobile education for the development of the structured method and tools for planning design automation by participating in the development of actual design automation systems. 


\section{DISCUSSION}

This papers research about the IoT for mobile education. Therefore, during the development for the system, they used an automating design methodology for the digital contents such as the lesson of the topic, videos and audios. However, this mobile education also for the students and instructors during the in or out class. Therefore, the decision making of the IoT in mobile education is important to interpretation of the level in technology mobile in century 21.

Nonetheless, expansion of the mobile education can support the online distance learning for the digital contents for students and instructors. In fact, IoT more beyond for the technology in development automating design for new environment for the smart university and colleage.

However, for the future technology, they can suggest for the Internet of Everything (IoE) and Internet of Nano Things (IoNT). This is new technology for the next generation to exploring in depth for the better services in technology internet.

Thus, for the security of things is an important to avoid a missing of data contents, virus, bootnet, spamming and identity theft.

\section{CONCLUSION}

In conclusion, IoT represents the next expansion of the Internet for mobile education. Given that humans advance and evolve by turning data into information, knowledge, and wisdom. Thus, the IoT has the potential to change the world as we know it today for the better education. How quickly to get there is up to them to learning a IoT for mobile education an environment in everywhere and anytime. Therefore, the IoT support for the next generation revolution in industrial as well in world.

However, especially for the students and instructors, IoT can help them a lot of the knowledge to explore more about the things and think like a visualisation for the better education. Next, it is to match of IoE and IoNT to more smart of things in University and College.

\section{REFERENCES}

1. Benisch, M., Kelley, P. G., Sadeh, N. \& Cranor, L. F. 2011. Capturing location-privacy preferences: quantifying accuracy and user-burden tradeoffs. Personal Ubiquitous Computing, 15, 679-694.

2. Berzowska, J. 2005. Memory rich clothing: second skins that communicate physical memory. In Proc. of C\&C, ACM Press, 32-40.

3. Brush, A. J. B., Lee, B., Mahajan, R., Agarwal, S., Saroiu, S. \& Dixon, C. 2011. Home Automation in the Wild:

4. Challenges and Opportunities. In Proc. CHI

5. Cafaro, F., Panella, A., Lyons, L., Roberts, J. \& Radinsky, J. 2013. I See You There! Developing Identity- Preserving Embodied Interaction for Museum Exhibits. In Proc, ACM Press, 1911-1920.

6. Carretero, J. \& García, J. D. 2013. The Internet of Things: connecting the world. Personal Ubiquitous Computing.

7. Davidoff, S., Zimmerman, J. and Dey, A.K. 2010. How Routine Learners can Support Family Coordination. In Proc.

8. CHI, ACM Press, 2461-2470.

9. Erickson, T., Li, M., Kim, Y., Deshpande, A., Sahu, S., Chao, T., Sukaviriya, P. \& Naphade, M. 2013. The Dubuque Electricity Portal: Evaluation of a City-Scale Residential Electricity Consumption Feedback System. In Proc. CHI, ACM Press, 1203-1212.

10. Gaver, W. W., Bowers, J., Boehner, K., Boucher, A., Cameron, D. W. T, Hauenstein, M., Jarvis, N. \& Pennington, S. 2013. Indoor Weather
Stations: Investigating a Ludic Approach to Environmental HCI Through Batch Prototyping. In Proc. CHI, ACM Press, 3451-3460.

11. Grosse-Puppendahl, T., Braun, A., Kamieth, F. \& Kuijper, A. 2013. Swiss-Cheese Extended: An Object

12. Recognition Method for Ubiquitous Interfaces based on Capacitive Proximity Sensing. In Proc. CHI, ACM Press, 1401-1410.

13. Mekael, C. 2007. Planning Design Automation: A Structured Method and Supporting Tools. School of Engineering, Chalmers University of Technology.

14. Harrison, C., Tan, D. \& Morris, D. Skinput: Appropriating the Body as an Input Surface. In Proc. CHI, ACM Press, 453-462.

15. Hong, X. \& Nugent, C. D. 2013. Segmenting sensor data for activity monitoring in smart environments. Personal Ubiquitous Computing, 17, 545-559.

16. Hynes, M., Wang, H., McCarrick, E. \& Kilmartin, L. 2011. Accurate monitoring of human physical activity levels for medical diagnosis and monitoring using off-theshelf cellular handsets. Personal Ubiquitous Computing, 15, 667-678.

\section{AUTHORS PROFILE}

I am Zairina Ibrahim, I am associated with Information Technology and Innovation Centre, Management and Science University, University Drive Seksyen 13,

Shah Alam 40100, Malaysia and my area of interest is internet and technology management.

I am Md Gapar Md Johar, I am associated with Information Technology and Innovation Centre, Management and Science University, University Drive Seksyen 13,

Shah Alam 40100, Malaysia and my area of interest is internet and technology management.

My name is Che Ku Nurul Hasmaria Che Ku Yahaya, is associated with Information Technology and Innovation Centre, Management and Science University, University Drive Seksyen 13, Shah Alam 40100, Malaysia and my area of interest is internet and technology management.

My name is Normy Rafida Abdul Rahman, I am from Faculty Business Management and Professional Studies, Management and Science University, University Drive Seksyen 13, Shah Alam 40100, Malaysia and my area of interest is internet and technology management. 